Service social

\title{
Méthodologie de recherche pour les intervenants sociaux, par Francine Ouellet et Robert Mayer, Boucherville, Gaëtan Morin éditeur, 1991, 537 pages.
}

\section{Richard Lefrançois}

Volume 41, numéro 2, 1992

Bilan des réformes

URI : https://id.erudit.org/iderudit/706574ar

DOI : https://doi.org/10.7202/706574ar

Aller au sommaire du numéro

Éditeur(s)

École de service social de l'Université Laval

ISSN

1708-1734 (numérique)

Découvrir la revue

Citer ce compte rendu

Lefrançois, R. (1992). Compte rendu de [Méthodologie de recherche pour les intervenants sociaux, par Francine Ouellet et Robert Mayer, Boucherville, Gaëtan Morin éditeur, 1991, 537 pages.] Service social, 41(2), 163-164.

https://doi.org/10.7202/706574ar d'utilisation que vous pouvez consulter en ligne.

https://apropos.erudit.org/fr/usagers/politique-dutilisation/ 


\section{RECENSIONS}

\section{MÉTHODOLOGIE DE RECHERCHE POUR LES INTERVENANTS SOCIAUX}

Francine Ouellet et Robert Mayer,

Boucherville, Gaëtan Morin éditeur, 1991, 537 pages.

On ne saurait trop insister sur cette idée maîtresse que « I'objet est souverain et non la méthode », message que nous confie d'entrée de jeu l'ouvrage en titre. Telle est la clef de lecture, la trame autour de laquelle s'échafaude ce livre. Plus qu'un recueil généreusement documenté d'axes et de stratégies de recherche sociale appliquée, l'ouvrage inscrit, dans une première partie, cette pratique scientifique au cœur même des contradictions et des débats dans lesquels elle se meut et construit sa spécificité. Même si le ton est sous le signe de la prudence, les auteurs parviennent, à travers une lecture historico-critique des moments forts dans l'abord du social, à nous convaincre de la nécessité de déverrouiller les univers trop cloisonnés de la doxe et de la praxis.

L'intuition présumée à l'origine de ce projet de livre a certes été de révéler aux lecteurs toute la richesse et l'applicabilité de l'instrumentation scientifique, en soulignant ses nombreux points d'ancrage aux réalités du travail auprès des personnes, des groupes ou des communautés. Travailleurs sociaux, formateurs, animateurs et apprenants deviennent, pour ainsi dire, les légataires privilégiés d'un corpus d'approches et de dispositifs de recherche extrêmement malléables et d'une utilité immédiate, susceptibles de soutenir une pluralité de projets de recherche et d'intervention.

II ne s'est pas agi ici, comme plusieurs I'ont entrepris, de vulgariser un savoir obscur et réservé, ni de distendre le rapport, houleux ou silencieux, entre chercheurs et intervenants, ni même $d^{\prime}$ 'inscrire une nouvelle interprétation de la méthode au contentieux opposant les tenants de l'approche quantitative à ceux de l'approche qualitative. Les auteurs ont préféré faire un choix plus judicieux, en optant pour la voie directe, pratique et éminemment pédagogique : celle de traduire dans un discours méthodologique clair la pertinence d'une démarche de recherche authentique et structurée qui tienne compte de l'ethos populaire, du vécu des populations cibles et de l'exigeante réalité professionnelle de l'interve- 
nant. Au fil des chapitres sont révélées la versatilité et l'ingéniosité des chercheurs en sciences humaines, la souplesse du langage de la recherche appliquée. Les auteurs tiennent manifestement en haute estime, à travers leurs exposés, ce projet de science et de société qu'est celui de la recherche sociale appliquée, ce qui ne manque pas de rehausser le statut épistémologique qui lui appartient en toute légitimité.

Un ouvrage de méthodologie ne peut certes se définir comme un guide clef en main de recettes universelles et éprouvées. Ce livre évite cet écueil. Ses auteurs comptent plutôt nous plonger dans l'univers passionnant de l'action, nous ouvrir au goût de la découverte, éveiller en nous le souci d'acquérir des attitudes et des postures scientifiques saines, nous rappeler la valeur de la rigueur scientifique en même temps qu'aiguiser constamment notre sens critique.

Cet ouvrage fécond et stimulant paraît aussi à un moment socio-historique crucial où l'État, en dépit de ses nombreux engagements sociaux, choisit de tirer sa révérence, où se nouent de nouvelles solidarités et où se profilent les contours d'un partenariat élargi. Les rôles du praticien se multipliant et se complexifiant, la nécessité pour le travailleur social de compter sur ses propres moyens ajoute à la pertinence de ce recueil de stratégies et de méthodes de recherche qui I'aidera à structurer son action de manière compétente tout en contribuant à raffermir son identité professionnelle.

La deuxième section de l'ouvrage initie le lecteur aux principaux axes de la recherche sociale. Sont amplement traités les dispositifs suivants : I'analyse de besoin, I'enquête conscientisante et militante, la recherche évaluative, la recherche féminine et la recherche-action. Ces scénarios de recherche s'accompagnent d'exposés finement documentés, s'éclairant d'exemples pertinents.

La troisième partie nous convie aux méthodes de l'observation, de collecte et d'analyse des données qualitatives, I'ensemble soutenant harmonieusement les différentes approches présentées précédemment. Des techniques trop souvent laissées dans l'ombre, telles que les récits de vie, le groupe nominal et la méthode Delphi, figurent également.

Nous aurions certes souhaité voir un chapitre sur les rudiments de l'analyse exploratoire et confirmatoire. Il faut cependant admettre que les traités de méthodologie quantitative ou statistique abondent dans la littérature. Aussi, il eût été approprié $d$ 'inclure des sections, même succinctes, sur les préceptes et fondements du travail scientifique, les protocoles expérimentaux, les règles procédurales de l'administration de la preuve, les sources de biais et la validation des instruments.

Nul doute que cet ouvrage suscitera un vif intérêt et qu'il connaîtra tout le succès qu'il mérite. 